\title{
Commentary: White matter changes in patients needing aortic arch surgery: A paramount matter!
}

\author{
Francesco Formica, MD, ${ }^{\mathrm{a}}$ and Stefano D'Alessandro, MD, FECTS ${ }^{\mathrm{b}}$
}

\footnotetext{
From the ${ }^{\mathrm{a} C a r d i a c}$ Surgery Unit, San Gerardo Hospital, Department of Medicine and Surgery, University of Milano-Bicocca, Monza, Italy; and ${ }^{\mathrm{b}}$ Cardiac Surgery Unit, Cardio-thoracic-vascular Department, San Gerardo Hospital Monza, Italy.

Disclosures: Authors have nothing to disclose with regard to commercial support.

Received for publication Nov 5, 2018; accepted for publication Nov 6, 2018; available ahead of print Dec 6, 2018.

Address for reprints: Francesco Formica, MD, Clinica Cardiochirurgica Ospedale San Gerardo, ASST Monza Via

G.B. Pergolesi 33, 20052, Monza (MB), Italy (E-mail: francesco formica@ fastwebnet.it).

J Thorac Cardiovasc Surg 2019;157:1358-9

$0022-5223 / \$ 36.00$

Copyright (c) 2018 by The American Association for Thoracic Surgery

https://doi.org/10.1016/j.jtcvs.2018.11.013
}

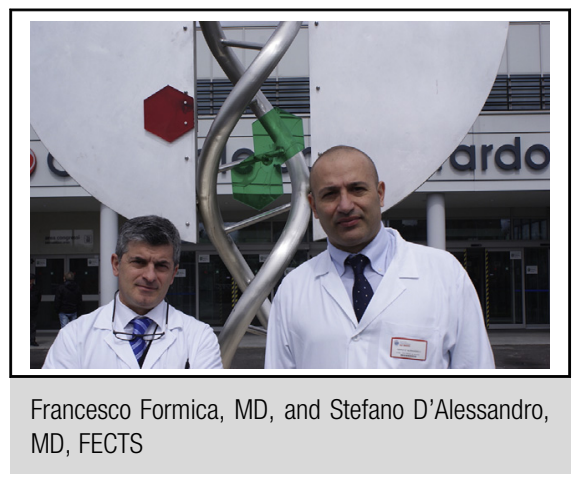

Central Message

Severe WMC is associated with reduced survival in patients who underwent aortic arch surgery. Preoperative imaging analysis of the WMC is of great importance for patient selection.

See Article page 1350. aneurysm has continued to increase because of the high prevalence of atherosclerosis disease, hypertension, diabetes, and advanced mean age. These conditions are associated with white matter changes (WMCs), ${ }^{1}$ and these changes are directly related to transient neurologic defects (TNDs) and permanent neurologic defects (PNDs) after thoracic aortic surgery. ${ }^{2,3}$ Because neurologic complications may negatively affect the early and late survival, ${ }^{2,4}$ preoperative evaluation of WMC by magnetic resonance imaging has emerged during the last decade. ${ }^{5}$ In this issue of the Journal, Ikeno and colleagues ${ }^{6}$ report interesting results regarding the correlation between the different grade of preoperative WMC severity and the incidence of neurologic outcome in patients who underwent total aortic arch replacement (TAAR) using antegrade cerebral perfusion. In their valuable retrospective study, the authors analyzed 359 consecutive patients eligible for TAAR who received preoperative magnetic resonance imaging to explore in depth the abnormality of white matter. Patients were divided into 3 groups according to the grading of WMC defined according to the Fazekas visual scale: mild, $\mathrm{n}=100$; moderate, $\mathrm{n}=158$; severe, $\mathrm{n}=101$. Patients with a severe WMC were older and presented with more comorbidities, including neurologic dysfunction and previous stroke, and therefore we can assume a high frailty index in these patients. The main findings of this study were as follows: (1) an overall low incidence of PND (2.2\%) and TND $(7.8 \%)$; (2) an increased incidence of neurologic complications according to the severity of WMC; and (3) patients with a severe WMC had a higher 1-year incidence of mortality (approaching 15\%) compared with the other 2 groups.

The results of this study provide important information about those patients with severe WMC who underwent TAAR with a high probability to have the worst prognosis.
At the same time, some questions arise from these results. Can older and frail patients be considered for a conservative approach rather than for conventional surgery? Frailty is reported as a factor that negatively affects midterm survival. $^{7,8}$ In those patients, a hybrid approach should be considered if the aortic disease is at high risk of imminent complications. Furthermore, is it correct to accept relatively high 1-year mortality in those patients with severe white matter abnormalities? Unfortunately, in this study the long-term survival probability is not reported, and these data could give some answers to the aforementioned questions. A recent meta-analysis ${ }^{9}$ reported that in more than 2000 patients who underwent aortic arch surgery, either with the conventional or hybrid approach, no differences were observed in terms of early mortality, neurologic events, renal failure, and prolonged ventilation. Moreover, the hazard ratio of 7-year survival was in favor of the hybrid approach (hazard ratio, 0.82; 95\% confidence interval, 0.69-0.99; $P=.04$ ). Ikeno and colleagues' study ${ }^{6}$ gives an important message to the readers: Given the complexity of TAAR and despite the evolution of the cerebral protection techniques, the incidence of neurologic complications is not negligible. Therefore, a more in-depth evaluation of a patient's preoperative neurologic conditions, aiming at selecting patients and providing an even more precise estimation of the operative risk, is of paramount matter. 


\section{References}

1. Van der Flier WM, van Straaten ECW, Barkhof F, Verdelho A, Madureira S, Pantoli L, et al; on behalf of the LADIS Study Group. Small vessel disease and general cognitive function in nondisabled elderly. Stroke. 2005;36:2116-20.

2. Lin R, Svensson L, Guota R, Lytle B, Krieger D. Chronic ischemic cerebral white matter disease is a risk factor for nonfocal neurologic injury after total aortic arch replacement. J Thorac Cardiovasc Surg. 2007;133:1059-65.

3. Obusez EC, Svensson L, Bullen J, Obuchowski N, Jones SE. Deep chronic microvascular white matter ischemic change as an independent predictor of acute brain infarction after thoracic aortic replacement. J Card Surg. 2018;33:552-60.

4. Di Eusanio M, Berretta P, Cefarelli M, Castrovinci S, Folesani G, Alfonsi J, et al. Long-term outcome after aortic arch surgery: result of a study involving 623 patients. Eur J Cardiothorac Surg. 2014;0:1-8.

5. Svensson L, Blackstone EH, Apperson-Hansen C, Ruggeri PM, Ainkaran P, Naugle RI, et al. Implications from neurologic assessment of brain protection

for total arch replacement from a randomized trial. J Thorac Cardiovasc Surg. 2015;150:1140-7.

6. Ikeno Y, Sasaki K, Matsueda T, Inoue T, Tanaka H, Sugimoto K, et al Impact of white matter changes on neurological outcomes of total arch replacement using antegrade cerebral perfusion. J Thorac Cardiovasc Surg. 2019;157:1350-7.e1.

7. Ganapathi AM, Englum BR, Hanna JM, Schechter MA, Gaca JG, Hurwitz LM, et al. Frailty and risk in proximal aortic surgery. J Thorac Cardiovasc Surg. 2014;147:186-91.

8. Hiraoka A, Saito K, Chikazawa G, Totsugawa T, Tamura K, Ishida A, et al. Modified predictive score based on frailty for mid-term outcomes in open total aortic arch surgery. Eur J Cardiothorac Surg. 2018;54:42-7.

9. Chakos A, Jabara D, Yan TD, Tian DH. Long-term survival and related outcomes for hybrid versus traditional arch repair - a meta-analysis. Ann Cardiothorac Surg. 2018;7:319-27. 